\title{
MÉTODO PARA AVALIAÇÃO DA QUALIDADE AMBIENTAL EM CONDOMÍNIOS RESIDENCIAIS HORIZONTAIS
}

\section{Method of environmental quality evaluation for horizontal residential condominiums}

\author{
Simone VALASKI ${ }^{1}$
}

\section{RESUMO}

Com base no Planejamento da Paisagem, sugere-se um método de avaliação da qualidade ambiental em condomínios residenciais horizontais. Parte-se do pressuposto de que esse tipo de condomínio apresente boa qualidade ambiental, já que pode ter sua implantação planejada como um todo. Foram escolhidos dezessete atributos que permitiram identificar a tendência positiva ou negativa da qualidade ambiental nos condomínios estudados.

Palavras-chave: Qualidade ambiental urbana; Planejamento da Paisagem; Condomínios residenciais horizontais.

\begin{abstract}
Based on Landscape Planning, it was proposed a method of environmental quality evaluation for horizontal residential condominiums. It has been taken for granted that this kind of condominium presents a good environmental quality, since it can have its implantation planned as a whole. Seventeen attributes were chosen which led at the identification of the positive or negative tendency of environmental quality in the analyzed condominiums.
\end{abstract}

Keywords: Urban environmental quality; Landscape Planning; Horizontal residential condominiums. com.br

1 Geógrafa, mestre e doutoranda em Geografia. Departamento de Geografia - UFPR (bolsista/CAPES). E-mail: svgeog@yahoo. 


\section{INTRODUÇÃO}

Uma forma de se ocupar o solo urbano que vem se propagando nas cidades brasileiras é o condomínio residencial horizontal. Muitos trabalhos acadêmicos tiveram como objeto de estudo este tipo de empreendimento. Entretanto, prevalecem nas pesquisas os aspectos econômicos, sociais e culturais, não sendo comum encontrar a temática ambiental, ou seja, a que trata do meio físico.

Diferentemente da ocupação que vai ocorrendo lote a lote, e com a expansão paulatina da zona urbana, que acaba não sendo tão bem planejada, espera-se que na implantação de um condomínio residencial horizontal a qualidade ambiental seja levada em consideração. Esta expectativa fundamenta-se nas características gerais deste tipo de empreendimento, incluindo-se o fato de se tratar de uma ocupação planejada, autorizada pela prefeitura, destinada à classe social com maior poder aquisitivo e geralmente realizada por empresas de renome compostas por profissionais gabaritados.

Com base no pressuposto acima, o trabalho buscou avaliar a qualidade ambiental em condomínios residenciais horizontais com base nos princípios do Planejamento da Paisagem.

O Planejamento da Paisagem caracteriza-se como um instrumento de relevância no direcionamento de ações administrativas relativas ao uso e ocupação do solo. A linha do Planejamento da Paisagem escolhida para a realização do presente trabalho é aquela que prioriza as questões ecológicas, buscando tirar o máximo proveito dos recursos naturais para diminuir o consumo de energia. Como exemplos de soluções práticas envolvendo tais princípios e que já foram testadas e estão sendo aplicadas tem-se a permacultura, as ecovilas e as ecohouses. Nesses casos existem aplicações de tecnologias que objetivam contribuir para a conservação dos recursos oferecidos pela natureza.

Buscou-se elaborar um método de avaliação, com base em determinados critérios e parâmetros, comparativa ou relativa de categorias de qualidade ambiental (maior ou positiva e menor ou negativa), evitando-se uma avaliação absoluta. Como áreas de teste, foram utilizados dois condomínios localizados no bairro Santa Felicidade - Curitiba/PR.

\section{CONDOMÍNIOS RESIDENCIAIS HORIZONTAIS}

Os condomínios fechados surgiram na década de 1950, nos Estados Unidos, quando se iniciou a aquisição de casas nos arredores das cidades, como segunda residência, sendo posteriormente cercadas. Entretanto, uma das primeiras comunidades construídas atrás de grades, com características semelhantes aos atuais condomínios fechados, data de 1885. Trata-se da comunidade de Tuxedo Park, próximo à Nova York. Neste mesmo período, ruas particulares, com grades, estavam sendo construídas em St. Louis e em outras cidades, em forma de mansões para as pessoas com elevado poder aquisitivo. Até as décadas de 1960 e 1970 estas comunidades eram raras e destinavamse somente à classe social mais abastada. Porém, tornou-se uma grande tendência na década de 1980 (BECKER, 2005).

Os condomínios residenciais horizontais ou "condomínios exclusivos" começaram a surgir nas grandes cidades brasileiras na década de 1970 (O'NEILL, 1986). Mais especificamente em 1975 foi inaugurado em São Paulo o AlphaVille, condomínio de uso misto (residencial, comercial e de serviços). Posteriormente, o AlphaVille, que se tornou um modelo de condomínio horizontal, implantou-se em outras grandes cidades como Campinas (1997), Belo Horizonte (1998), Curitiba (2000), Goiânia (2002), dentre outras e também em Portugal (DACANAL, 2004; ALBUQUERQUE et al., 2003).

As possibilidades de uma vida mais segura, em contato com a natureza e em alto estilo, são apelos veiculados pelas construtoras no momento da venda destes empreendimentos.

Segundo Caldeira (2000, p.265) a definição de condomínios colocada pelo marketing os compara a ilhas: "os anúncios apresentam a imagem de ilhas para as quais pode se retornar todos os dias para escapar da cidade e para encontrar um mundo exclusivo de prazer entre iguais."

Delicato (2004) coloca que, embora em escala menor, assim como a questão da segurança, a preocupação ecológica é incorporada a um ideal de moradia que renega a cidade nos moldes atuais. Os empreendedores exploram as deficiências da cidade e apostam em vender qualidade de vida associando valores ecológicos aos condomínios lançados no mercado imobiliário.

A imagem dos condomínios horizontais, como uma paisagem urbana ideal, aproxima-se da imagem do paraíso terrestre. A ideia de que um condomínio horizontal é um lugar ideal para habitar foi rapidamente incorporada, pois é muito mais fácil construir uma imagem em relação a um espaço novo do que desconstruir e reconstruir imagens em relação a espaços degradados, que precisam ser revitalizados. É mais fácil incorporar uma nova imagem do que transformar a imagem do 
"velho", pois isto implica em requalificar. E requalificar não significa apenas reformar o espaço físico: implica em mudanças de conduta, em desconstruções conceituais, em conscientizar-se ambientalmente (DACANAL, 2004).

\section{PLANEJAMENTO DA PAISAGEM}

O Planejamento da Paisagem surge como uma proposta de ordenamento dos usos do solo sob a perspectiva de uma conciliação entre as necessidades que caracterizam a sociedade moderna e os efeitos que a intervenção humana causa sobre o meio físico. Desta forma, percebe-se o vínculo existente entre o Planejamento da Paisagem e a preocupação com a qualidade ambiental. O Planejamento da Paisagem caracteriza-se na atualidade como um instrumento de suma importância na organização e distribuição dos usos na paisagem.

É na Alemanha que o Planejamento da Paisagem atual encontra suas raízes mais profundas. Suas rotas passadas podem ser traçadas a partir da melhoria da paisagem e dos movimentos de embelezamento do início do século XIX e da herança do movimento natural e cultural que surgiu no final do século XIX, em contraposição à industrialização e ao crescimento da destruição da natureza. Naquele país, o Planejamento da Paisagem, um importante instrumento de planejamento para a proteção, gerenciamento e desenvolvimento completo da paisagem, foi colocado pela primeira vez em forma de lei através da Lei Federal de Conservação da Natureza de 1976 (KIEMSTEDT et al., 1998; NUCCI, 1998; PECCIOLI FILHO, 2005).

No campo do Planejamento da Paisagem outros autores fora da Alemanha merecem destaque pela realização de trabalhos voltados para um planejamento da ocupação do solo que leve em consideração as potencialidades (limites e aptidões) da paisagem. Dentre estes autores podem ser citados McHarg (1969), Tricart (1977), Gómez Orea (1978), Marsh (1998), entre outros.

O objetivo principal do Planejamento da Paisagem é proteger a capacidade funcional do ecossistema e a forma das paisagens de um modo sustentável e duradouro. É, portanto, um dos mais importantes instrumentos de planejamento no campo da proteção ambiental. As contribuições dadas pelo Planejamento da Paisagem mostram que o uso da terra deve levar em conta a suscetibilidade e a capacidade de recuperação dos recursos naturais. Estas contribuições aplicam-se para áreas habitadas ou não servindo, deste modo, para finalidades como a estruturação do ambiente próximo a regiões residenciais e da aparência de paisagens utilizadas com fins de recreação (KIEMSTEDT et al., 1998).

Cavalheiro et al (1987 apud NUCCI, 1998) organizaram uma listagem na qual são colocadas as condições básicas a se considerar no Planejamento da Paisagem:

- Respeito ao potencial do meio ambiente

- Valorização das relações da natureza

- Atingir uma melhor integração homem / natureza

- Respeito às condições culturais (sociais, econômicas, etnográficas, etc.)

- Participação da comunidade nas decisões

O Planejamento da Paisagem caracteriza-se como um instrumento de preservação e utilização da natureza com o objetivo de salvaguardar a capacidade dos ecossistemas e a potencialidade recreativa da paisagem como partes fundamentais da vida humana. As principais metas do Planejamento da Paisagem são:

- $\quad$ proteger a diversidade animal e vegetal e suas biocenoses por meio do desenvolvimento de uma rede interligada de áreas protegidas, renaturalização de cursos d'água, revegetação, reflorestamento, entre outros.

- $\quad$ proteger as paisagens, seus elementos e os espaços livres em áreas urbanas para fornecer a oportunidade de contato contemplativo e recreativo com a natureza. As áreas precisam ser designadas e protegidas do impacto visual, ruídos e poluição.

- proteger o solo, a água e o clima por meio de regulamentação dos usos e regeneração dos recursos. Controle do escoamento superficial (runoff), da permeabilidade dos solos, dos aquíferos, da poluição. Utilização da vegetação como forma de controle (KIEMSTEDT et al., 1998; NUCCI, 1998).

As metas acima mencionadas e os princípios gerais, encontrados na revisão bibliográfica, e que caracterizam o Planejamento da Paisagem, não foram 
suficientes para se construir um método de avaliação da qualidade ambiental dos condomínios residenciais horizontais. Para organizar critérios e parâmetros para a avaliação, buscou-se, portanto, as indicações de três sistemas de planejamento e projetos que levam em consideração o respeito às potencialidades da paisagem: a permacultura, a ecovila e a ecohouse. Em cada um destes casos são encontradas muitas técnicas e ações que resultam em uma relação mais harmoniosa entre 0 homem e a natureza, o que está em consonância com os princípios colocados pelo Planejamento da Paisagem.

\section{PERMACULTURA, ECOVILA E ECOHOUSE}

Os graves problemas ambientais na atualidade trouxeram à tona reflexões sobre as possíveis modificações na maneira do ser humano se comportar em relação à natureza, já que os recursos que a natureza oferece para a sobrevivência humana são limitados.

As práticas da permacultura, da ecovila e da ecohouse trazem soluções que permitem uma utilização dos recursos naturais de maneira mais racional, ou seja, com diminuição dos impactos ambientais negativos.

\section{PERMACULTURA}

A permacultura é um sistema de planejamento que tem como objetivo criar ambientes humanos sustentáveis. Seus princípios teóricos e práticos são uma síntese das práticas agrícolas e conhecimentos tradicionais e das descobertas da ciência moderna visando o desenvolvimento integrado da propriedade. Este sistema oferece as ferramentas para o planejamento, a implantação e a manutenção de ecossistemas cultivados no campo e nas cidades, de modo a que eles tenham a diversidade, a estabilidade e a resistência dos ecossistemas naturais. Alimento saudável, habitação e energia devem ser providos de forma racional para criar culturas permanentes. A Permacultura exige uma mudança de atitude que consiste basicamente em fazer os seres humanos viver de forma integrada ao meio ambiente, alimentando os ciclos vitais da natureza.

Começando com a ética e com os princípios focados no domínio crítico da eficácia de gestão da terra e da natureza, a permacultura é envolvida pela aplicação progressiva para a integração de todos os sete domínios necessários para uma cultura sustentável. Os sete domínios apresentados nos princípios permaculturais são: gestão da terra e natureza; posse da terra e governo comunitário; finança e economia; saúde e bem-estar espiritual; cultura e educação; ferramentas e tecnologia; e construção ambiental (HOLMGREN, 2001).

\section{ECOVILA}

Existem vários conceitos para se definir uma ecovila, porém, em todos eles pode-se observar que prevalece uma visão comunitária, integrada e sustentável. De acordo com Gilman (1991 apud SANTOS JR., 2006) o conceito de ecovila pode ser entendido como um assentamento humano caracterizado pela integração das atividades humanas com o mundo natural de maneira a não lhe causar danos e que permitam o desenvolvimento humano saudável.

As ecovilas são consideradas modelos de comunidades intencionais ou comunidades sustentáveis. A ideia de Ecovilas foi incorporada pelas Nações Unidas no Programa de Desenvolvimento de Comunidades Sustentáveis (SCDP). Esse movimento encontra-se interligado com o princípio da permacultura. Encontrar alternativas que fortaleçam os pequenos assentamentos humanos no Brasil, transformando-os em ecovilas, significa reduzir as pressões sobre as cidades. Podese sugerir que as ecovilas sejam aplicadas no entorno de parques e unidades de conservação para reduzir a pressão da população humana sobre as áreas protegidas (ECOVILAS, 2003). Também se pode pensar nas ecovilas como uma zona de amortecimento entre a zona urbana e a zona rural.

De maneira geral, as ecovilas estão embasadas em quatro elementos fundamentais:

- 1) Infraestrutura: sistemas de captação, armazenamento, distribuição e reciclagem da água; sistemas de geração de energia renovável; redução das necessidades de transporte; acesso à comunicação.

- 2) Produção e consumo de alimentos e necessidades básicas

- 3) Arquitetura e construções ecológicas: considerações sobre o ciclo de vida dos materiais; restauração dos ecossistemas naturais.

- 4) Estruturas sociais e econômicas: decisão e governo em nível local; sistemas econômicos 
locais; sistemas de saúde preventiva; educação para a realidade; estruturas culturais.

\section{ECOHOUSE}

De acordo com Roaf et al (2006, p.11) "[...] os edifícios são os poluentes mais nocivos, consumindo mais da metade de toda a energia usada nos países desenvolvidos e produzindo mais da metade de todos os gases que vêm modificando o clima."

Adam (2001) coloca que para poder sustentar o desregrado consumo de energia dos edifícios, houve um grande crescimento da produção de energia elétrica, causando forte impacto ambiental devido à construção de usinas, inundações, deslocamentos de populações, perda de biodiversidade, bem como poluição e riscos de segurança pública com termoelétricas e usinas nucleares.

Humberto Colombo, presidente na década de 1980 da Comissão Italiana para Energia Nuclear e Fontes Alternativas de Energia, complementa a questão, relacionada com o consumo energético, ao afirmar que um componente deste panorama é aquele de como se consome energia e não só de como se produz. Somente um modo de viver e consumir diferente (não só energia) pode assegurar um futuro aceitável. Não se trata de um fato técnico e econômico é, sobretudo, um fato cultural e requer longo tempo de amadurecimento. Energética e edifício interferem-se estreitamente, são dimensões diversas sobre as quais se projetam os mesmos problemas (ADAM, 2001).

Segundo Edwards e Hyett (2004), os habitats criados pelos arquitetos devem contribuir para satisfazer tanto as necessidades humanas como de outras espécies. A biodiversidade é responsabilidade de todos: arquitetos, engenheiros, agricultores, políticos e cidadãos. Os arquitetos podem desempenhar um importante papel de três maneiras:

- 1. Fazendo da criação de habitats naturais uma parte integrante do projeto arquitetônico: plantio de árvores, coberturas ajardinadas, muros cobertos com plantas trepadeiras;

- 2. Selecionando os materiais de construção com sensibilidade ecológica, com a finalidade de manter a biodiversidade local ou regional por meio de produtos ou materiais utilizados;

- 3. Favorecendo o contato com a natureza, por meio do plantio de espécies vegetais no interior e exterior do edifício e aproveitando as vistas da paisagem natural. $O$ objetivo é tanto material como espiritual. Trata-se de conseguir que a espécie humana não esteja desconectada do mundo natural.

Um estímulo para que se tenha uma maior área com vegetação nos lotes urbanos seria a regressão no imposto municipal. Ou seja, edificações que tivessem, por exemplo, um jardim, uma trepadeira no muro, uma árvore na calçada ou telhado verde, poderiam ter redução no valor de impostos prediais e territoriais $(\mathrm{NUCCl}$, 2001).

$\mathrm{Na}$ Alemanha existe um grande interesse na introdução e preservação do verde nos lotes e edificações urbanas. Existe no país uma classificação dos tipos de superfícies, associando-se a elas um valor (fator de multiplicação). Este fator de multiplicação é utilizado nos cálculos do desconto no imposto urbano (BERLIM, 2007).

Uma construção que cause um mínimo impacto ambiental e que tenha um máximo aproveitamento energético faz parte de muitos projetos atualmente. Dentro os itens que contribuem para uma melhor qualidade ambiental podem ser citados: captação e reutilização da água da chuva; reutilização das águas servidas; utilização da vegetação arbórea pensando-se no conforto térmico; aproveitamento da energia solar; telhados verdes; biodigestor; distribuição das edificações no terreno de maneira a aproveitar a insolação.

\section{MÉTODO DE AVALIAÇÃO DA QUALIDADE AMBIENTAL EM CONDOMÍNIOS RESIDENCIAIS HORIZONTAIS}

A elaboração de um método de avaliação da qualidade ambiental em condomínios residenciais horizontais foi sendo delineada por meio da busca, na literatura, de elementos que pudessem enquadrar-se na proposta de minimização da poluição no ambiente e na redução do consumo de energia. Desta forma, foram listados os atributos que tem influência na qualidade ambiental. Estes atributos foram divididos em gerais e específicos. Os atributos gerais foram analisados no condomínio como um todo, no conjunto. Os atributos específicos relacionam-se com a edificação dentro do condomínio. 
Os atributos de ordem geral, ou seja, aqueles que se referem à análise do conjunto foram denominados de atributos mensuráveis, constituídos em seis aspectos:

- 1. Cobertura vegetal arbórea

- 2. Espaços livres de edificação

- 3. Opções de recreação ao ar livre

- 4. Permeabilidade do solo

- 5. Forma do arruamento

- 6. Distância mínima entre as edificações

Os dados referentes aos atributos mensuráveis foram obtidos com o uso de imagens de satélite disponibilizadas no Google Earth. Com base nas imagens, foram feitas as delimitações aproximadas dos atributos para que, posteriormente, fossem realizados os cálculos necessários. A escala aproximada das imagens utilizadas foi de 1:2.500, o que tornou possível a identificação de muitos detalhes do condomínio. As delimitações, bem como os cálculos, tiveram um resultado aproximado, mas que permitem a avaliação da qualidade ambiental.

Foram escolhidos alguns valores que serviram de parâmetro para se considerar um determinado atributo como tendo maior ou menor qualidade ambiental. A avaliação quantitativa foi realizada considerando uma escala de gradação de qualidade ambiental usando-se três denominações: POSITIVA, MEDIANA e NEGATIVA. Quanto à denominação POSITIVA, não significa que determinado atributo faz com que o condomínio tenha obrigatoriamente ótima qualidade ambiental, mas que contribui para que a qualidade ambiental possa ser melhor. No caso da MEDIANA, significa que o atributo ainda precisa de alguns ajustes para contribuir mais eficazmente com a melhora da qualidade ambiental. Quanto à NEGATIVA, não significa que a qualidade ambiental é nula, mas que há uma tendência à baixa qualidade ambiental. Deste modo, não se pretende dar uma resposta radical se o condomínio tem ou não qualidade ambiental, mas mostrar suas tendências.

Ainda no tocante à avaliação geral, foram escoIhidos mais três atributos, denominados de atributos objetivos, cujos dados não puderam ser obtidos por meio da imagem de satélite ou não poderiam ser avaliados da mesma maneira que os seis itens anteriormente citados. Neste caso, os atributos tiveram como resultado SIM ou NÃO, sendo que a resposta SIM foi considerada como positiva para a qualidade ambiental e a NÃO como negativa. Estes atributos são:

- 1. Biodigestor

- 2. Reciclagem de resíduos sólidos

- 3. Reservatório para água de escoamento superficial

Para a avaliação de ordem específica, ou seja, a que diz respeito às edificações, foi elaborada uma lista com oito atributos, que também tiveram como resposta SIM ou NÃO. Estes atributos são:

- 1. Captação e uso de águas pluviais

- 2. Reaproveitamento de águas servidas

- 3. Placas fotovoltaicas

- 4. Aquecimento solar de água

- 5. Aproveitamento da luz solar para iluminação no interior da edificação

- 6. Telhado verde

- 7. Vegetação (conforto térmico)

- $\quad$ 8. Vegetação nas fachadas

Com base na literatura foram escolhidos parâmetros de avaliação para cada atributo, conforme segue.

\section{ATRIBUTOS MENSURÁVEIS}

\section{COBERTURA VEGETAL ARBÓREA (CVA)}

De acordo com a revisão bibliográfica são inúmeros os benefícios que a vegetação traz no ambiente urbano, contribuindo para a qualidade ambiental.

De acordo com Oke (1973 apud LOMBARDO, 1985) um índice de cobertura vegetal na faixa de $30 \%$ seria o recomendável para proporcionar um adequado balanço térmico em áreas urbanas, sendo que um índice de arborização inferior a 5\% determina características semelhantes à de um deserto.

Para este atributo foi considerada a porcentagem deCVA em relação à área total do condomínio. Os critérios estabelecidos foram:

POSITIVA: > 25\% / MEDIANA: entre 20 e $25 \%$ / NEGATIVA $<20 \%$ 
O cálculo de CVA dos condomínios foi feito levando-se em consideração todas as manchas de copas de árvores que puderam ser identificadas na imagem de satélite.

\section{ESPAÇOS LIVRES DE EDIFICAÇÃO (ELE'S)}

O conceito de espaço livre utilizado no presente trabalho é o proposto por Cavalheiro et al (1999): espaços urbanos ao ar livre, destinados a todo tipo de utilização que se relacionem com caminhadas, descanso, passeios, práticas de esporte e, em geral, a recreação e entretenimento em horas de ócio; os locais onde as pessoas se locomovem por meios motorizados não devem ser considerados como espaços livres. Os espaços livres podem ser privados, potencialmente coletivos ou públicos e podem desempenhar, principalmente, funções de estética, de lazer e de ecológico-ambiental, entre outras.

Por meio da análise de literatura, as sugestões menos restritivas de índices de espaços livres urbanos variam de aproximadamente $4 \mathrm{a} 10 \mathrm{~m}^{2} / \mathrm{hab}$. para áreas junto às habitações e unidades de vizinhança (NUCCI, 1996).

Para a avaliação dos espaços livres dos condomínios, foram considerados os espaços livres de edificação e que são de uso comum (público), não sendo considerado o sistema viário. Neste cálculo estão inseridos todos os espaços que não são edificados, sendo consideradas as áreas para prática recreativa, como quadras, playgrounds e piscinas. Os critérios escolhidos para avaliar este atributo foram:

POSITIVA: $>10 \mathrm{~m}^{2} /$ hab / MEDIANA: entre 5 e $10 \mathrm{~m}^{2} / \mathrm{hab} / \mathrm{NEGATIVA}:<5 \mathrm{~m}^{2} / \mathrm{hab}$

\section{OPÇÕES DE RECREAÇÃO AO AR LIVRE}

Como complemento ao atributo anteriormente apresentado, fez-se o cálculo dos espaços destinados à recreação ao ar livre. Foram consideradas as áreas onde existe algum tipo de equipamento que induza as pessoas a alguma atividade ao ar livre como, por exemplo, quadras poliesportivas, playgrounds e piscinas. Estes espaços fazem parte dos espaços livres de edificação. Deste modo, o atributo apresentado neste item contribui, também, para uma avaliação qualitativa parcial dos ELE's. Os critérios utilizados para este atributo foram os mesmos utilizados nos ELE's, ou seja:
POSITIVA: $>10 \mathrm{~m}^{2} /$ hab / MEDIANA: entre 5 e $10 \mathrm{~m}^{2} / \mathrm{hab} / \mathrm{NEGATIVA}:<5 \mathrm{~m}^{2} / \mathrm{hab}$

\section{PERMEABILIDADE DO SOLO}

Os altos índices de impermeabilização do solo urbano têm como resultado direto o aumento do escoamento superficial e a diminuição da infiltração das águas pluviais. Consequentemente, aumenta-se a probabilidade de ocorrência de enchentes.

Em Nordhein-Westfalen (Alemanha) considerase como ponto crítico que um município utilize mais de $50 \%$ de sua superfície para construção. Na Hungria são feitos esforços para não permitir que mais de $50 \%$ dos terrenos urbanizáveis sejam edificados ou pavimentados (NUCCl, 1999).

Os valores calculados para este atributo consideram a porcentagem de área do condomínio que não foi impermeabilizada. Nos condomínios que ainda não tinham todos os seus lotes edificados, fez-se uma média para a ocupação do lote. Os critérios escolhidos para avaliar a permeabilidade do solo foram:

POSITIVA: > 50\% / MEDIANA: entre 45 e $50 \%$ / NEGATIVA: $<45 \%$

\section{FORMAS DE ARRUAMENTO}

O penúltimo atributo mensurável que foi avaliado é o que estava relacionado com as formas do arruamento, ou seja, o desenho das ruas dentro do condomínio.

Comumente, a forma de arruamento mais usada nas cidades brasileiras é o tabuleiro de xadrez. Entretanto, do ponto de vista da qualidade ambiental, outras formas podem ser consideradas mais apropriadas. Uma opção seria o arruamento chamado cul-de-sac. Este desenho é caracterizado por presença de uma única via principal, onde circula o trânsito mais intenso, e vias secundárias terminadas em cul-de-sac. Nesta opção de desenho, podem ser colocados sistemas de controle de velocidade para veículos, reduzindo o ruído local e os riscos para os pedestres.

Outra importante questão relacionada ao desenho do arruamento diz respeito aos espaços livres. A forma de tabuleiro de xadrez induz a uma diminuição dos espaços livres, enquanto a forma cul-de-sac permite que exista um ganho de espaços livres. 
VALASKI, S. Método para avaliação da qualidade ambiental em condomínios residenciais horizontais

Para estabelecer os critérios para avaliar as formas do arruamento nos condomínios foram considerados os seguintes detalhes de desenho:

- Desenho 1: arruamento com uma via principal de tráfego mais intenso e ruas secundária em cul-de-sac;

- Desenho 2: presença de vias secundárias mas sem uma via principal bem definida;

- Desenho 3: presença de uma única via principal, sem ramificações, ou tabuleiro de xadrez.

De acordo com os detalhes do desenho expostos acima, foram estabelecidos os critérios para avaliação. Estes critérios são:

POSITIVA: Desenho $1 /$ MEDIANA: Desenho 2 / NEGATIVA: Desenho 3

\section{DISTÂNCIA MÍNIMA ENTRE AS EDIFICAÇÕES}

O distanciamento entre edificações tem relação com a insolação, o aumento de área permeável e a circulação de correntes de ar. Quanto maior for a dis- tância entre as residências maior será o aproveitamento da incidência dos raios solares na edificação. Também ocorre um ganho de espaço entre as edificações que pode ser ocupado por vegetação.

O valor mais alto encontrado em pesquisa de campo como distância mínima entre edificações foi de $6 \mathrm{~m}$. Entretanto, quando se considera que em muitos condomínios são construídas residências com um terceiro pavimento, este valor mínimo passa a ser questionado, pois pode ocorrer o sombreamento da edificação vizinha. Deste modo, os critérios estabelecidos para avaliar a distância mínima entre as edificações foram:

POSITIVA: $>6 \mathrm{~m} /$ MEDIANA: entre 5 e $6 \mathrm{~m}$ / NEGATIVA: $<5 \mathrm{~m}$

\section{ATRIBUTOS OBJETIVOS E ESPECÍFICOS}

Os atributos que têm como resposta SIM ou NÃO foram organizados em uma lista de checagem (QUADRO 1). As respostas foram obtidas por meio de visitas aos condomínios e aproveitamento de informações contidas em folders e/ou internet. Também foram incluídos na ficha de levantamento alguns itens que podem auxiliar na confirmação de dados obtidos com a análise da imagem de satélite, como a área total do condomínio, o número de lotes e o número de moradores.

\begin{tabular}{|c|c|c|c|c|}
\hline \multicolumn{5}{|l|}{ Condomínio: } \\
\hline \multicolumn{5}{|l|}{ Endereço: } \\
\hline Área total $\left(m^{2}\right)$ : & $\mathrm{N}^{0}$ de lotes: & & & $\mathrm{N}^{0}$ de moradores: \\
\hline \multicolumn{5}{|c|}{ ATRIBUTOS OBJETIVOS } \\
\hline \multicolumn{2}{|l|}{ ITENS } & SIM & NÃO & OBSERVAÇÕES \\
\hline \multicolumn{5}{|l|}{ 1. Biodigestor } \\
\hline \multicolumn{5}{|l|}{ 2. Reciclagem de resíduos sólidos } \\
\hline \multicolumn{5}{|c|}{ 3. Reservatório para água de escoamento superficial } \\
\hline \multicolumn{5}{|c|}{ ATRIBUTOS ESPECÍFICOS } \\
\hline ITENS & & SIM & NÃO & OBSERVAÇÕES \\
\hline \multicolumn{5}{|c|}{ 1. Captação e uso de águas pluviais } \\
\hline \multicolumn{5}{|c|}{ 2. Reaproveitamento de águas servidas } \\
\hline \multicolumn{5}{|l|}{ 3. Placas fotovoltaicas } \\
\hline \multicolumn{5}{|l|}{ 4. Aquecimento solar da água } \\
\hline \multicolumn{5}{|c|}{$\begin{array}{l}\text { 5. Aproveitamento da luz solar para iluminação no } \\
\text { interior da edificação }\end{array}$} \\
\hline \multicolumn{5}{|l|}{ 6. Telhado verde } \\
\hline \multicolumn{5}{|l|}{ 7. Vegetação (conforto térmico) } \\
\hline 8. Vegetação nas fachadas & & & & \\
\hline
\end{tabular}

QUADRO 1 - FICHA PARA LEVANTAMENTO DOS ATRIBUTOS OBJETIVOS E ESPECÍFICOS

FONTE: VALASKI (2008) 
Para melhor visualização dos atributos escoIhidos e dos parâmetros estabelecidos, o método foi organizado em um fluxograma (Figura 1).

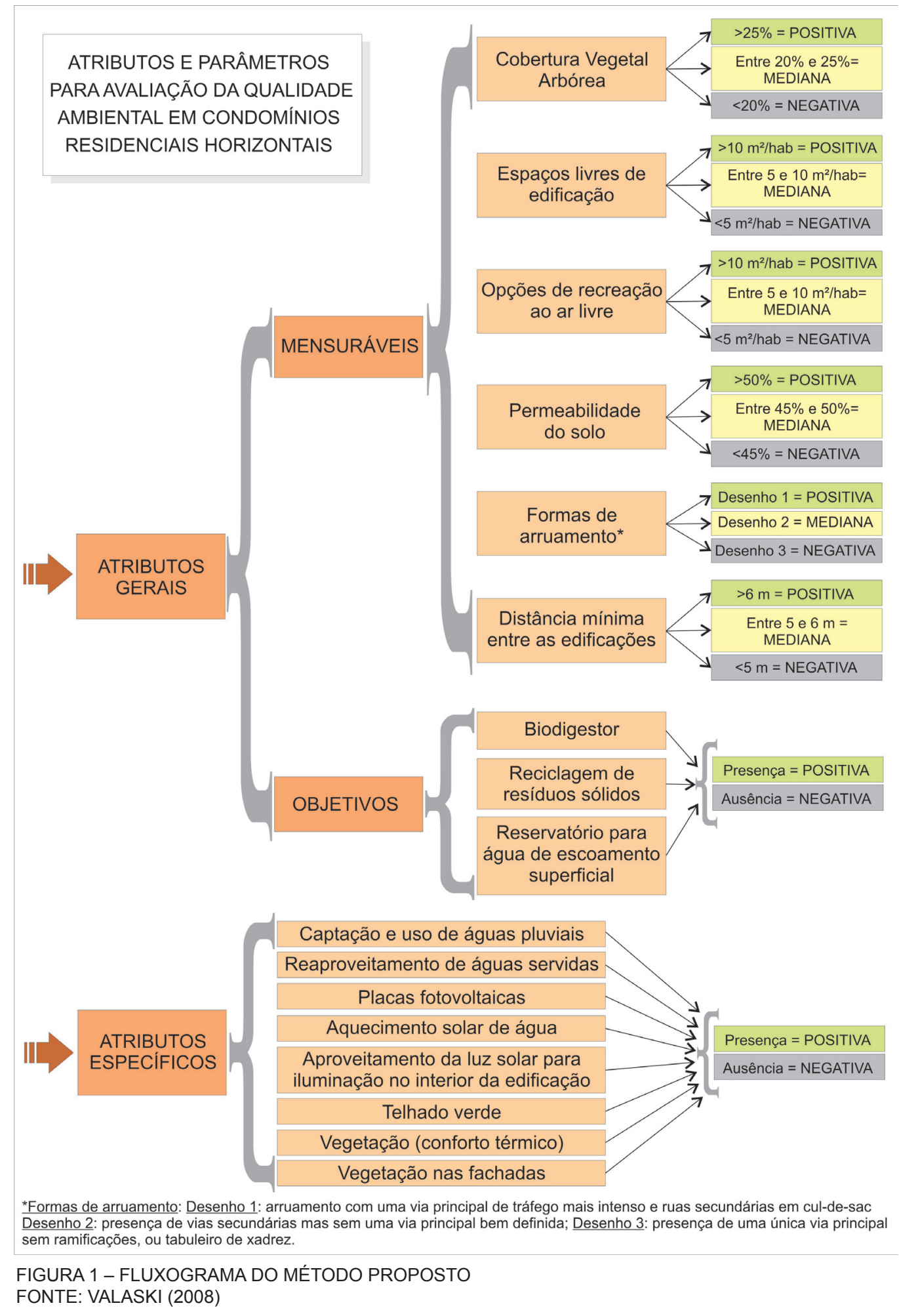




\section{APLICAÇÃO DO MÉTODO}

O método proposto foi aplicado em dois condomínios existentes no bairro Santa Felicidade que se localiza na porção norte de Curitiba a $7 \mathrm{Km}$ do Centro, ocupando uma área de $12,27 \mathrm{~km}^{2}$, que corresponde a $2,85 \%$ da área total do município (Figura 2).

Nesse bairro foram e estão sendo construídos muitos condomínios residenciais horizontais. Por meio de levantamento de campo, realizado no ano de 2007 , foi possível localizar 76 condomínios no bairro (VALASKI, 2008).

A proposta de método é um dos resultados da dissertação de mestrado (VALASKI, 2008) na qual foram avaliados seis condomínios no bairro. Entretanto, a título de exemplo, para este artigo foram escolhidos apenas dois condomínios, com características bem diferenciadas entre si. Os nomes e endereços dos condomínios foram omitidos para se evitar a apropriação indevida das informações.

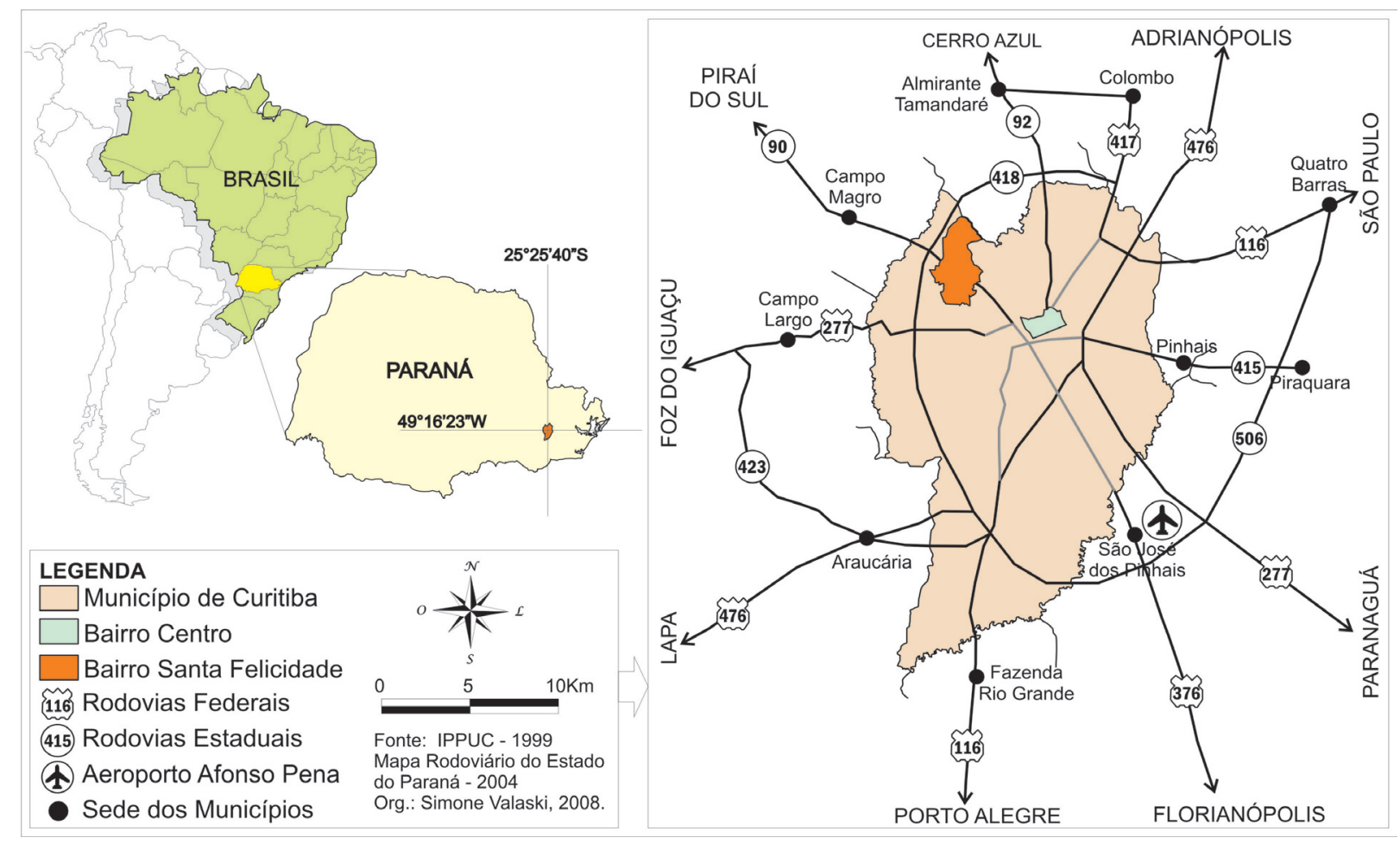

FIGURA 2 - LOCALIZAÇÃO DO BAIRRO SANTA FELICIDADE - CURITIBA/PR

FONTE: VALASKI (2008)

As figuras 3 e 4 apresentam as imagens de satélite com os contornos dos condomínios escolhidos para avaliação. 


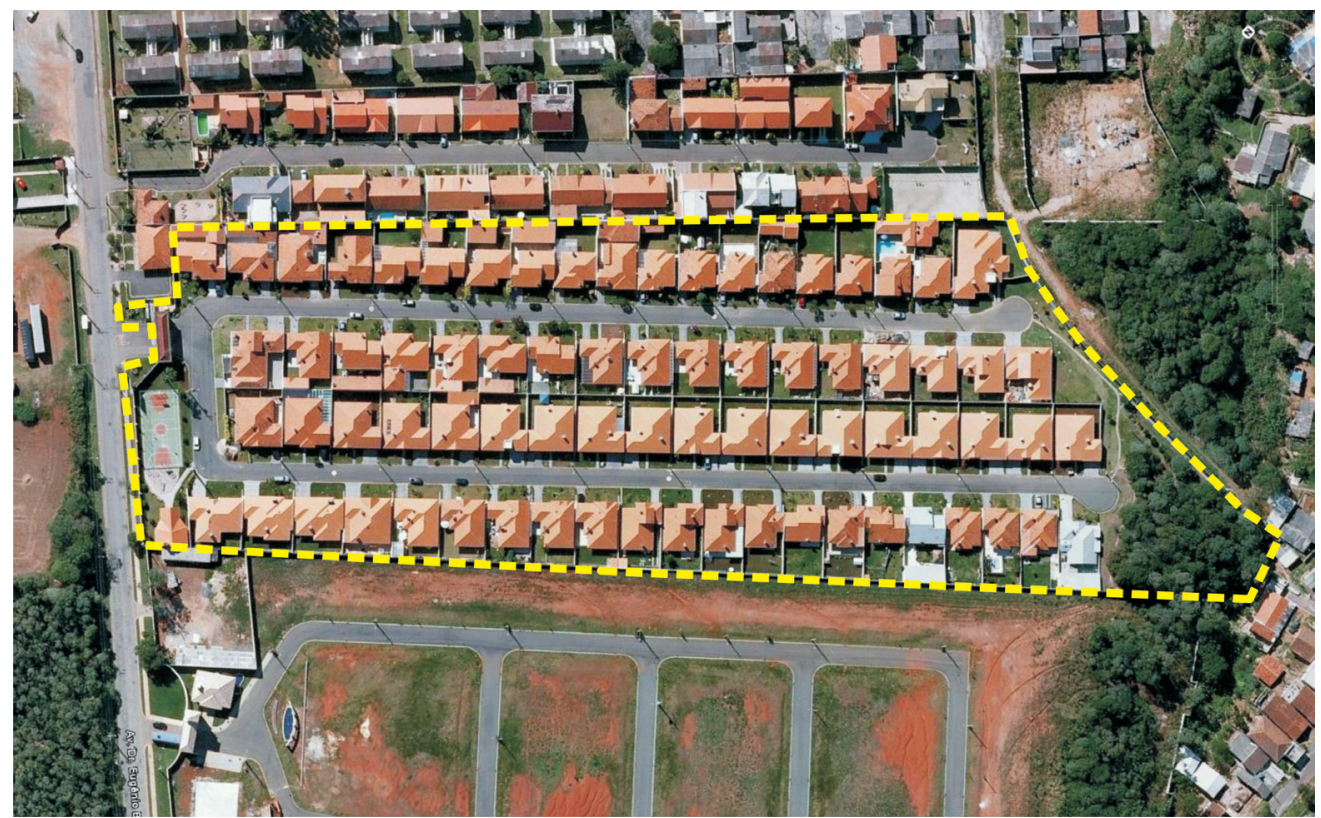

FIGURA 3 - IMAGEM DE SATÉLITE COM A DELIMITAÇÃO DO CONTORNO DO CONDOMÍNIO № 1 FONTE: GOOGLE EARTH (2006)

Org.: Simone Valaski, 2008.

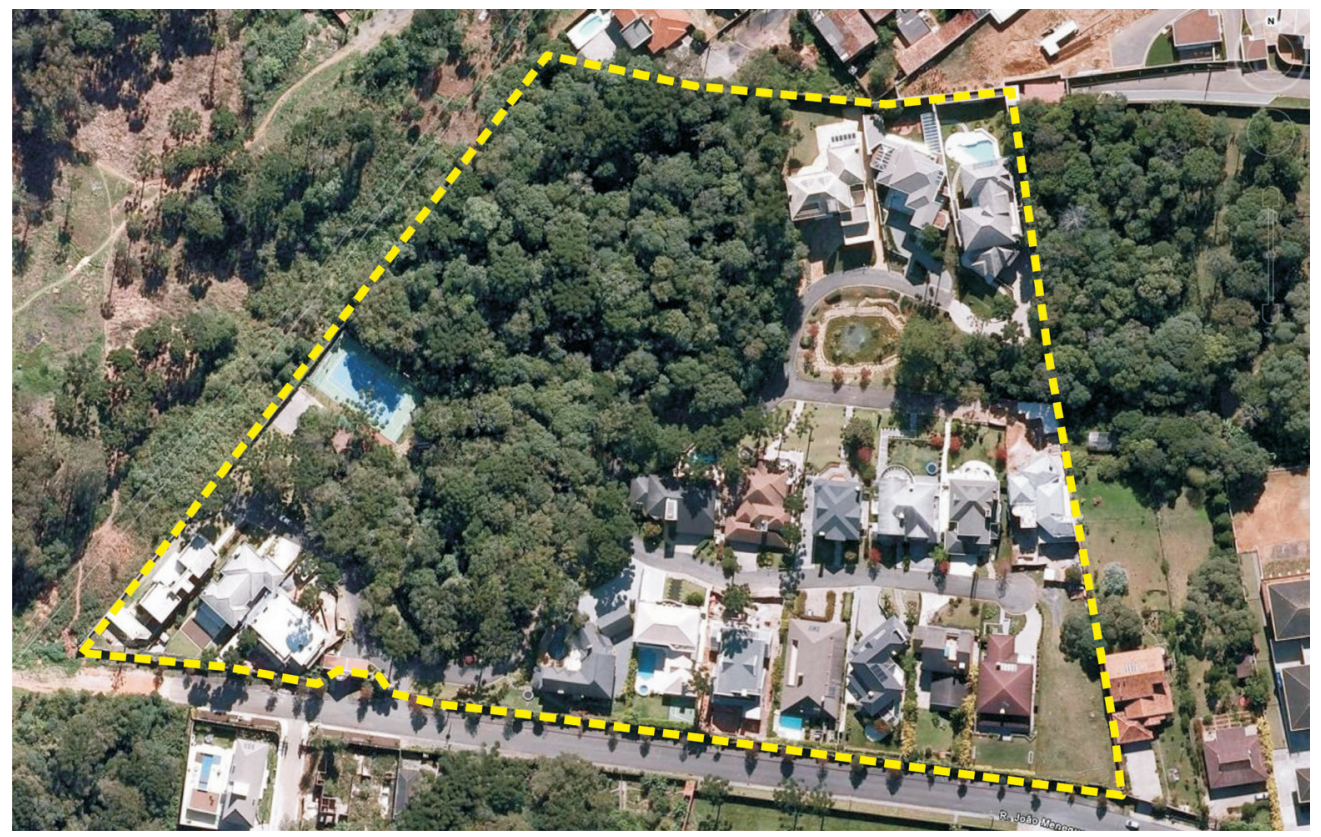

FIGURA 4 - IMAGEM DE SATÉLITE COM A DELIMITAÇÃO DO CONTORNO DO CONDOMÍNIO Nº 2 FONTE: GOOGLE EARTH (2006)

Org.: Simone Valaski, 2008. 
Com base na imagem de satélite foi possível obter os valores para os atributos mensuráveis. Cada atributo foi desenhado sobre a imagem, separadamente. Após o cálculo, fez-se a comparação com os parâmetros estabelecidos para cada atributo, classificando-os como positivos, medianos ou negativos.
As figuras 5 e 6 apresentam os valores encontrados para cada atributo nos condomínios 01 e 02 respectivamente, bem como um croqui representando a delimitação de cada atributo separadamente. No caso da distância mínima entre as edificações foram apenas apresentados os valores.

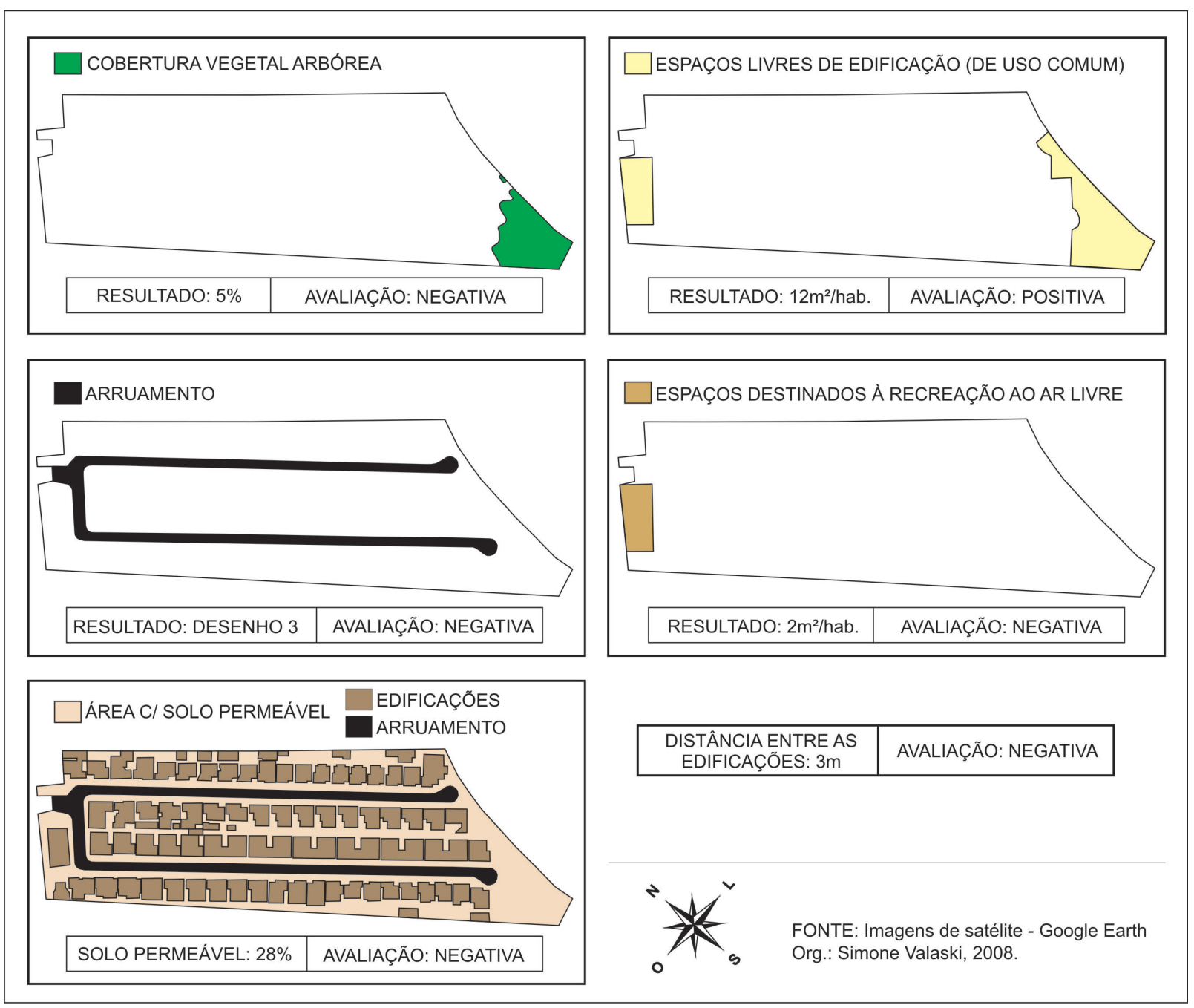

FIGURA 5 - CROQUIS E RESULTADOS DOS ATRIBUTOS MENSURÁVEIS DO CONDOMÍNIO N 1 FONTE: VALASKI (2008) 

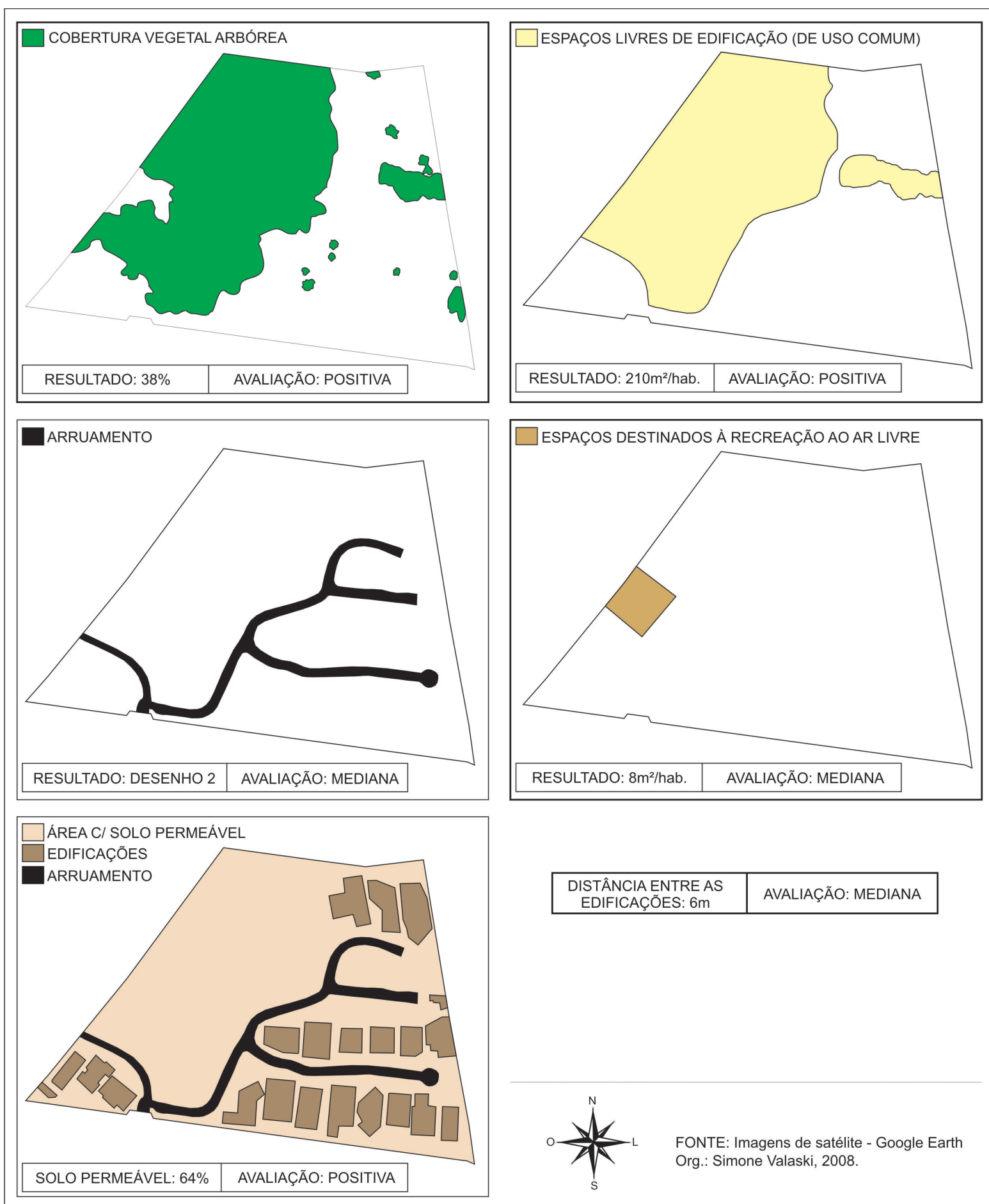

FONTE: Imagens de satélite - Google Earth Org.: Simone Valaski, 2008.

FIGURA 6 - CROQUIS E RESULTADOS DOS ATRIBUTOS MENSURÁVEIS DO CONDOMÍNIO № 2 FONTE: VALASKI (2008) 
VALASKI, S. Método para avaliação da qualidade ambiental em condomínios residenciais horizontais

Após a obtenção dos resultados dos atributos objetivos foi possível fazer a avaliação geral dos condomínios. Para isto, os dados encontrados foram organizados em uma tabela. (Tabela 1)

TABELA 1 - RESULTADOS DOS ATRIBUTOS GERAIS

\begin{tabular}{c|c|c}
\hline \multirow{2}{*}{ ATRIBUTOS } & $\mathbf{0 1}$ CONDOMINOS \\
\cline { 2 - 3 } Cobertura vegetal arbórea & $5 \%$ (negativa) & $38 \%$ (positiva) \\
\hline Espaços livres de edificação & $12 \mathrm{~m}^{2} / \mathrm{hab}$ (positiva) & $210 \mathrm{~m}^{2} / \mathrm{hab}$ (positiva) \\
\hline Recreação ao ar livre & $2 \mathrm{~m}^{2} / \mathrm{hab}$ (negativa) & $8 \mathrm{~m}^{2} / \mathrm{hab}$ (mediana) \\
\hline Permeabilidade do solo & $28 \%$ (negativa) & $64 \%$ (positiva) \\
\hline Formas de arruamento & Desenho 3 (negativa) & Desenho 2 (mediana) \\
\hline Distância mínima entre as edificações & $3 \mathrm{~m}$ (negativa) & $6 \mathrm{~m}$ (mediana) \\
\hline Biodigestor & NÃO & NÃO \\
\hline Reciclagem de resíduos sólidos & SIM & SIM \\
\hline AVALIAçÃo GERAL & SIM & SIM \\
\hline
\end{tabular}

FONTE: VALASKI (2008)

O condomínio $\mathrm{n}^{\circ} 1$ apresentou resultado negativo quanto à qualidade ambiental. Dos nove atributos avaliados, apenas três tiveram avaliação positiva: o índice de espaços livres, a reciclagem de resíduos sólidos e a presença de reservatório para água de escoamento superficial. Deste modo, este condomínio teve como avaliação uma tendência negativa quanto à qualidade ambiental.

O condomínio $n^{\circ} 2$ teve apenas um atributo negativo, a inexistência de biodigestor. Na classificação mediana foram encontrados três atributos: recreação ao ar livre, forma de arruamento e distância entre as residências. Cinco atributos tiveram avaliações positivas, merecendo destaque o percentual de cobertura vegetal arbórea e o alto índice de espaços livres. A avaliação deste condomínio foi considerada como tendo uma tendência positiva em relação à qualidade ambiental.

Complementado a proposta de avaliação da qualidade ambiental nos condomínios, fez-se uma pesquisa com atributos que se relacionassem diretamente com a edificação dentro do condomínio. Estes atributos foram organizados em uma lista de checagem e os dados obtidos em visita aos condomínios e aos plantões de venda dos empreendimentos. A tabela 2 apresenta os resultados obtidos para cada atributo em cada um dos condomínios avaliados. 


\begin{tabular}{c|c|c}
\hline \multirow{2}{*}{ ATRIBUTOS } & \multicolumn{2}{|c}{ CONDOMíNIOS } \\
\cline { 2 - 3 } & $\mathbf{0 1}$ & $\mathbf{0 2}$ \\
\hline Captação e uso da água da chuva & NÃO & NÃO \\
\hline Reaproveitamento de águas servidas & NÃO & NÃO \\
\hline Placas fotovoltaicas & NÃO & NÃO \\
\hline Aquecimento solar de água & NÃO & NÃO \\
\hline Aproveitamento da luz solar: iluminação no interior da edificação & SIM & SIM \\
\hline Telhado verde & NÃO & NÃO \\
\hline Vegetação (conforto térmico) & NÃO & NÃO \\
\hline Vegetação nas fachadas & NÃO & NÃO \\
\hline
\end{tabular}

FONTE: VALASKI (2008)

$\mathrm{Na}$ avaliação específica os resultados foram os mesmos para os dois condomínios. Apenas um atributo teve resposta positiva: o aproveitamento da luz solar para iluminação do interior das edificações. Nos dois condomínios as residências são construídas com amplas janelas. A construtora responsável pelo condomínio $\mathrm{n}^{\circ} 1$ tem nos seus projetos a colocação de grandes janelas de maneira que, durante o dia, não seja necessária a utilização de lâmpadas.

Quanto ao aquecimento solar, algumas poucas residências têm instalado este equipamento. Entretanto, a iniciativa é do proprietário do imóvel, e não da construtora.

Deste modo, a avaliação específica foi considerada negativa para a qualidade ambiental, já que apenas um dos atributos teve resultado positivo.

\section{CONCLUSÃO}

Os resultados mostraram a tendência positiva da qualidade ambiental em um condomínio, mas, apenas na avaliação geral. A edificação propriamente dita não apresenta tendências de projetos que objetivem alterar o modo convencional de construção. A presença de aque- cedor solar de água, encontrada em algumas casas, foi uma iniciativa do proprietário e não da construtora responsável pelo empreendimento.

Existe ainda uma grande resistência em incluir nos projetos itens que contribuam com a diminuição do consumo de energia e diminuição da poluição, como as placas fotovoltaicas, a captação e uso da água da chuva, a reutilização das águas servidas, a utilização de telhado verde, entre outros.

O método mostrou-se eficaz para se ter uma ideia da tendência da qualidade ambiental nos condomínios. Com a aplicação deste método, é possível acompanhar com certa facilidade o desenvolvimento urbano. A comunidade pode monitorar se a qualidade ambiental do bairro está aumentando ou diminuindo com a construção de condomínios e até de outras intervenções urbanísticas, já que o Planejamento da Paisagem prevê também a participação popular.

Outra característica positiva em relação ao método é a facilidade de obtenção das imagens de satélite, já que estas imagens estão disponíveis gratuitamente na internet, não sendo necessária a requisição de material junto aos órgãos públicos. Dos nove atributos gerais propostos no método, seis podem ser obtidos por meio da análise destas imagens. 
VALASKI, S. Método para avaliação da qualidade ambiental em condomínios residenciais horizontais

\section{REFERÊNCIAS}

ADAM, R. S. Princípios do ecoedifício: interação entre ecologia, consciência e edifício. São Paulo: Aquariana, 2001. 128p.

ALBUQUERQUE, R.; IVAN, M.; MARTINI, L. F. Viver a vida Alphaville: Alphaville 30 anos. Săo Paulo: M. I. Marketing, 2003. 224p.

BECKER, D. Condomínios horizontais fechados: avaliação de desempenho interno e impacto físico espacial no espaço urbano. 308 p. Dissertação (Mestrado em Planejamento Urbano e Regional) - PROPUR, UFRGS, Porto Alegre, 2005.

BERLIM. Berlin Digital Environmental Atlas. 2007. Disponível em: <http://www.stadtentwicklung.berlin.de/umwelt/ umweltatlas/edua_index.shtml>. Acesso em: 07/11/2007.

CALDEIRA, T. P. R Cidade de muros: crime, segregação e cidadania em São Paulo. São Paulo: Edusp, 2000.

CAVALHEIRO, F.; NUCCI, J. C.; GUZZO, P.; ROCHA, Y.T. Proposição de terminologia para o verde urbano. Boletim Informativo da SBAU (Sociedade Brasileira de Arborização Urbana), Rio de Janeiro, ano vii, n. 3, p. 7, jul./set. 1999.

DACANAL, C. Acesso Restrito: reflexões sobre a qualidade ambiental percebida por habitantes de condomínios horizontais. 192 p. Dissertação (Mestrado em Geografia) Instituto de Geociências e Ciências Exatas, Universidade Estadual Paulista, Rio Claro, 2004.

DELICATO, C.T. Faces de Marília: a moradia em um condomínio. 124 p. Dissertação (Mestrado em Ciências Sociais) - Faculdade de Filosofia e Ciências, Universidade Estadual Paulista Júlio de Mesquita Filho, Marília, 2004.

ECOVILAS - Um Modelo Ambiental Presente no Século XXI. 2003. Disponível em: <http://www.arq.ufsc.br/arq5661/ trabalhos_2003-1/ecovilas/conceito.htm>. Acesso em: 06/05/ 2007.

EDWARDS, B.; HYETT, P. Guia básica de la sostenibilidad. Barcelona: Editorial Gustavo Pili, 2004. 121p.

GOOGLE EARTH. Bairro Santa Felicidade - Curitiba/PR. 2006.

GÓMEZ OREA, D. El médio físico y la planificacion. Madri: CIFCA, 1978, v. I e II, 307p.

HOLMGREN, D. The essence of permaculture. 2001. Disponível em: <http://www.nelsonnavelar.com/permacultura/ $\mathrm{img} /$ The-Essence-of-Permaculture.pdf $>$. Acesso em: 08/02/07.

KIEMSTED, H.; von HAAREN, C.; MÖNNECKE, M.; OTT, S. Landscape Planning: contents and procedures. Hanover: The Federal Ministry for the Environment, Nature Conservation and Nuclear Safety, Universidade de Hanover, 1998, 39p.
LOMBARDO, M. A. Ilha de calor nas metrópoles: o exemplo de São Paulo. São Paulo: Hucitec, 1985. 244p.

McHARG, I. Design with nature. Nova York: Back Edition, 1969, 198p.

MARSH, W. M. Landscape planning. Environmental Applications. $3^{\text {th }}$ Edition. New York: John Wiley \& Sons, Inc., 1998, 434p.

NUCCI, J. C. Metodologia para determinação da qualidade ambiental urbana. São Paulo: DG-FFLCH-USP. Revista do Departamento de Geografia, n. 12, p. 209-224, 1998.

. Análise sistêmica do ambiente urbano: adensamento e qualidade ambiental. Revista de Ciências Biológicas e do Ambiente, PUC, v. 1, n. 1, p. 73-88, 1999.

Qualidade ambiental e adensamento urbano. São Paulo: Humanitas/Fapesp, 2001, 236 p.

Qualidade ambiental e adensamento: um estudo de planejamento da paisagem do distrito de Santa Cecília (MSP). Tese (Doutorado) - Departamento de Geografia, FFLCH-USP. São Paulo, 1996.

O’NEILL, M.M.V.C. Condomínios exclusivos: um estudo de caso. Revista Brasileira de Geografia. Rio de Janeiro: IBGE, n. 48, p.63-81, 1986.

PECCIOLI FILHO, R. C. Planejamento da paisagem na bacia hidrográfica do rio Palmital - RMC/PR: delimitação de unidades de paisagem como suporte ao planejamento urbano. $115 \mathrm{p}$. Dissertação (Mestrado em Geografia) - Departamento de Geografia, UFPR, Curitiba, 2005.

ROAF, S.; FUENTES, M.; THOMAS, S. Ecohouse - a casa ambientalmente sustentável. 2. ed. Porto Alegre: Bookman, 2006, 408p.

SANTOS JÚNIOR, S. J. dos. Ecovilas e comunidades intencionais: ética e sustentabilidade no viver contemporâneo. In: ENCONTRO DA ASSOCIAÇÃO NACIONAL DE PÓSGRADUAÇÃO E PESQUISA EM AMBIENTE E SOCIEDADE, 3., 2006, Brasília, DF. Anais... Brasília: ANPPAS. 1 CDROM.

TRICART, J. Ecodinâmica. Rio de Janeiro: IBGE, 1977.

VALASKI, S. Avaliação da qualidade ambiental em condomínios residenciais horizontais com base nos princípios do planejamento da paisagem. Estudo de caso: bairro Santa Felicidade - Curitiba - PR. 138 p. Dissertação (Mestrado em Geografia) - Departamento de Geografia, UFPR, Curitiba, 2008. 